
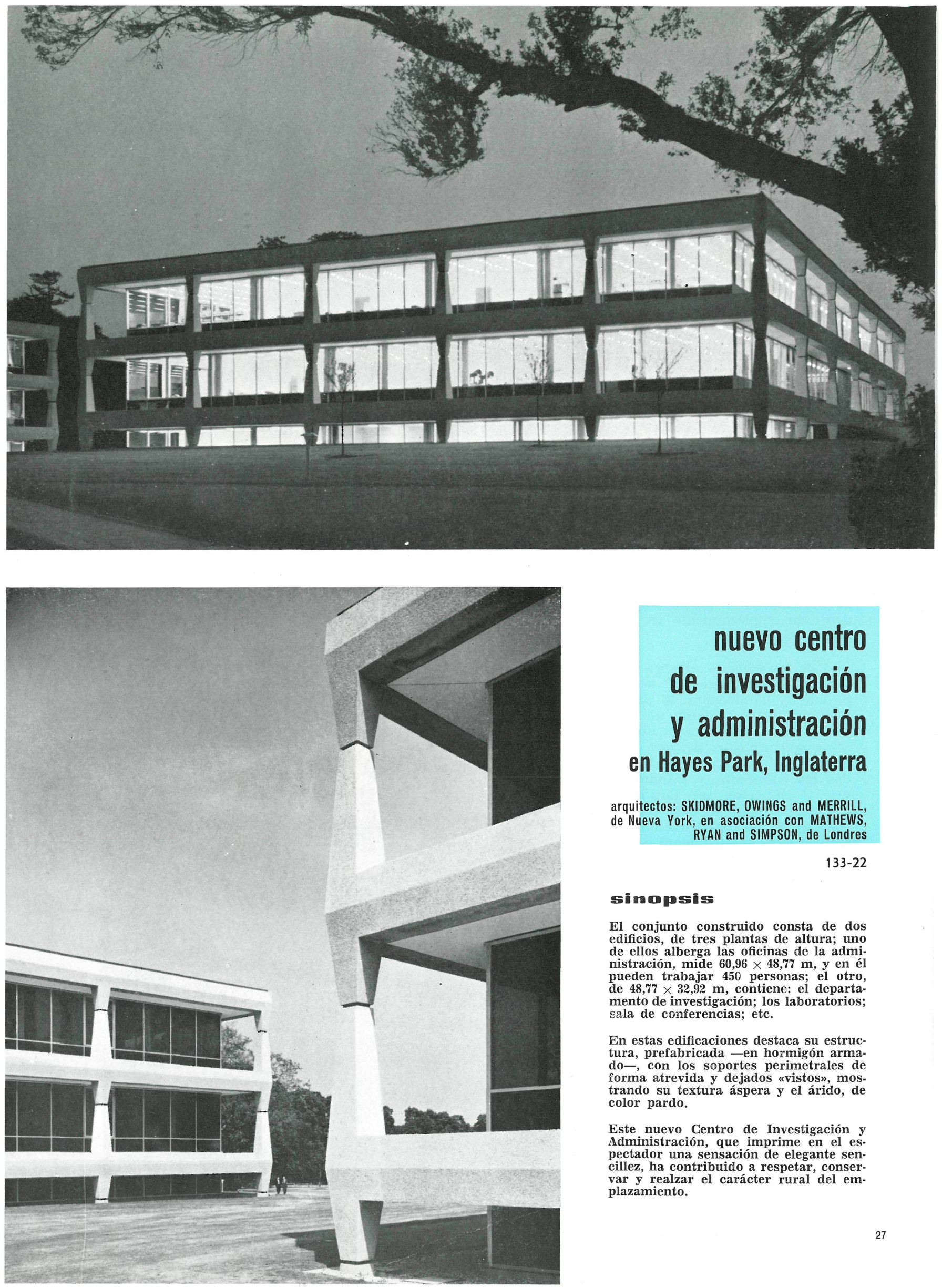

\title{
nuevo centro de investigación y administración en Hayes Park, Inglaterra
}

arquitectos: SKIDMORE, OWINGS and MERRILL, de Nueva York, en asociación con MATHEWS, RYAN and SIMPSON, de Londres

$133-22$

\section{simopsis}

El conjunto construido consta de dos edificios, de tres plantas de altura; uno de ellos alberga las oficinas de la administración, mide $60,96 \times 48,77 \mathrm{~m}$, y en él pueden trabajar 450 personas; el otro, de $48,7 \% \times 32,92 \mathrm{~m}$, contiene: el departamento de investigación; los laboratorios; sala de conferencias; etc.

En estas edificaciones destaca su estructura, prefabricada - en hormigón armado-, con los soportes perimetrales de forma atrevida y dejados «vistos», mos. trando su textura áspera y el árido, de color pardo.

Este nuevo Centro de Investigación y Administración, que imprime en el espectador una sensación de elegante senvar y realzar el carácter rural del emplazamiento. 


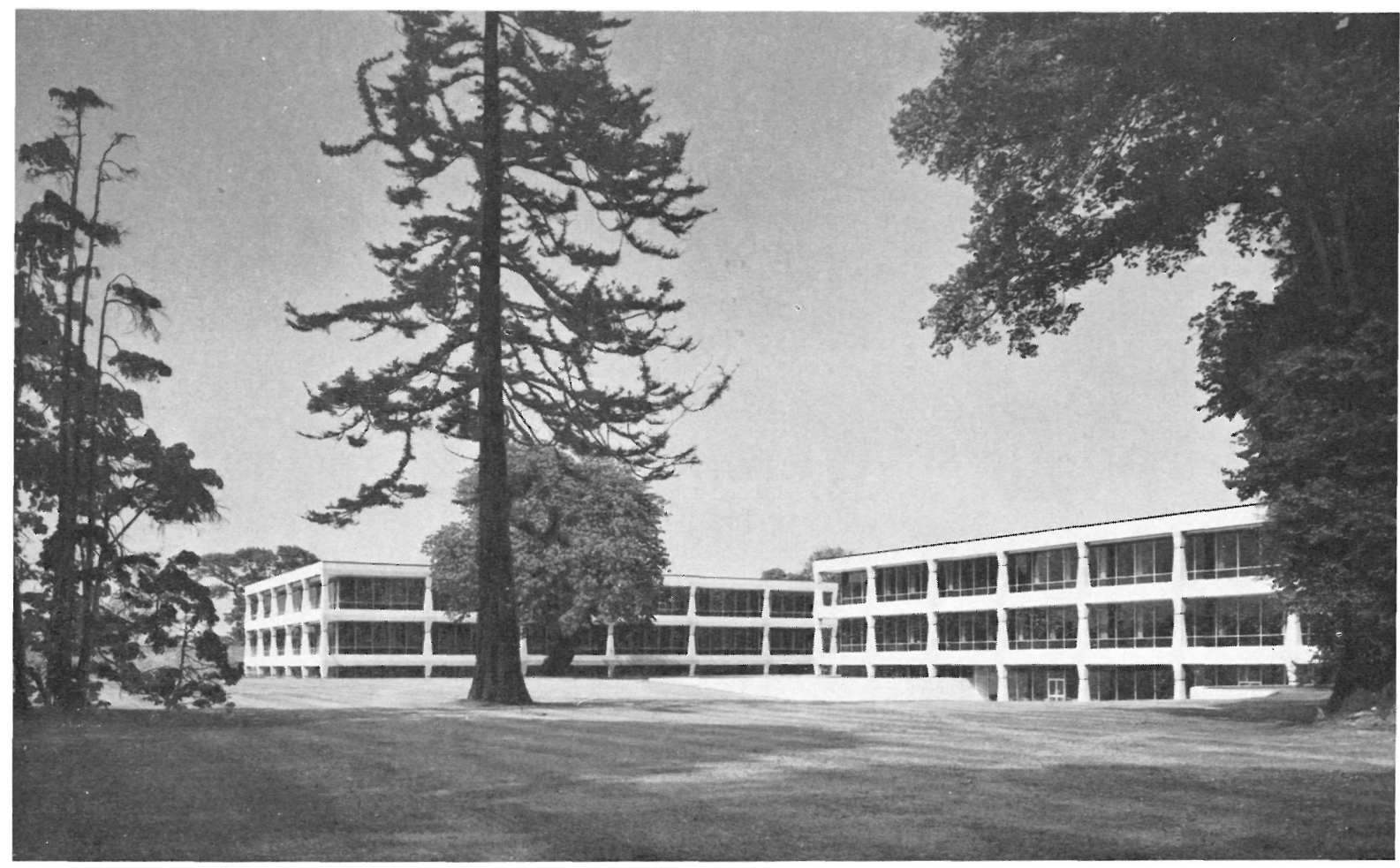

La Sociedad H. J. Heinz Co. Ltd., ha trasladado sus departamentos de investigación y administración desde su emplazamiento en Harlesden a las dos nuevas edificaciones que ha erigido en Hayes Park, Hayes, Middlesex.

Uno de los edificios alberga las oficinas de la administración, y el otro: los laboratorios y el departamento de investigación; la unión entre ellos se logró mediante un paso subterráneo, lo que hizo posible la eliminación de pasos cubiertos y permitió disponer de un área circundante despejada. Los arquitectos tuvieron un especial cuidado en conservar los árboles más bellos existentes, algunos de los cuales ahora están iluminados; talar determinadas zonas de bosque y replantearlas, en ciertas áreas con arbustos floridos, con objeto de conseguir el actual entorno urbanístico, que constituye una hermosa distracción para todos los empleados y visitantes, y en crear un jardín vallado, tratado a base de vegetación, un bello recinto natural para aparcamiento de vehículos.

Los dos edificios emplazados de forma que se complementan mutuamente, fueron proyectados al borde de una zona verde partiendo de la idea de conservar y realzar el carácter rural del emplazamiento, modulados según un módulo de 1,422 m y diseñados con un aspecto arquitectónico que destaca por su elegante sencillez.

Dichos edificios, que constan de dos plantas elevadas sobre el nivel general del terreno circundante y otra más por debajo de él, no solamente han proporcionado unas mejores condiciones para la labor de investigación de la

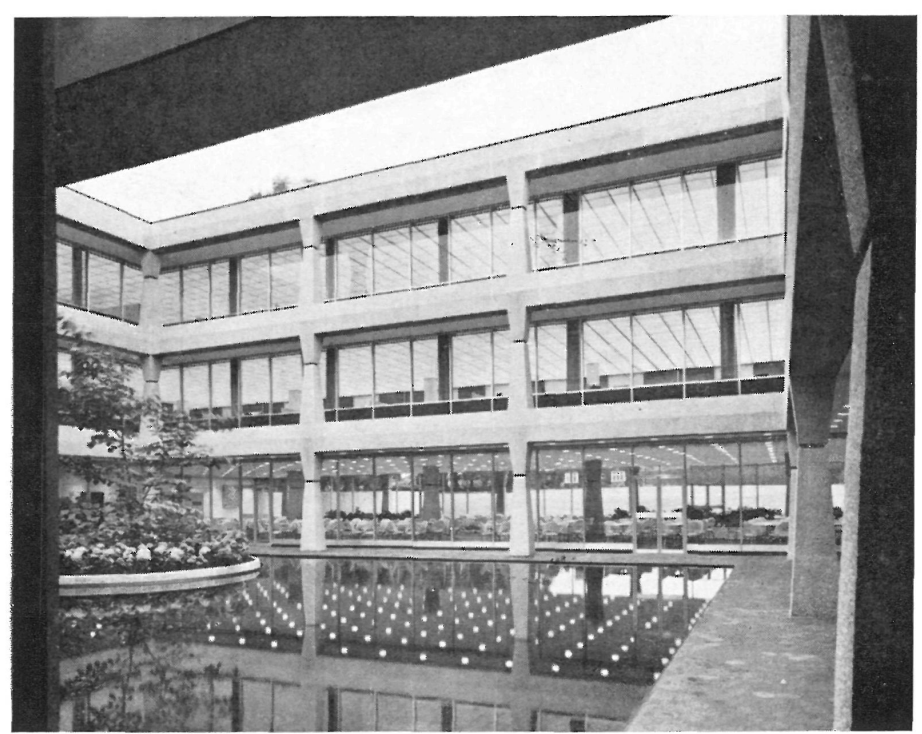

Fotos: EZRA STOLLER, associates 


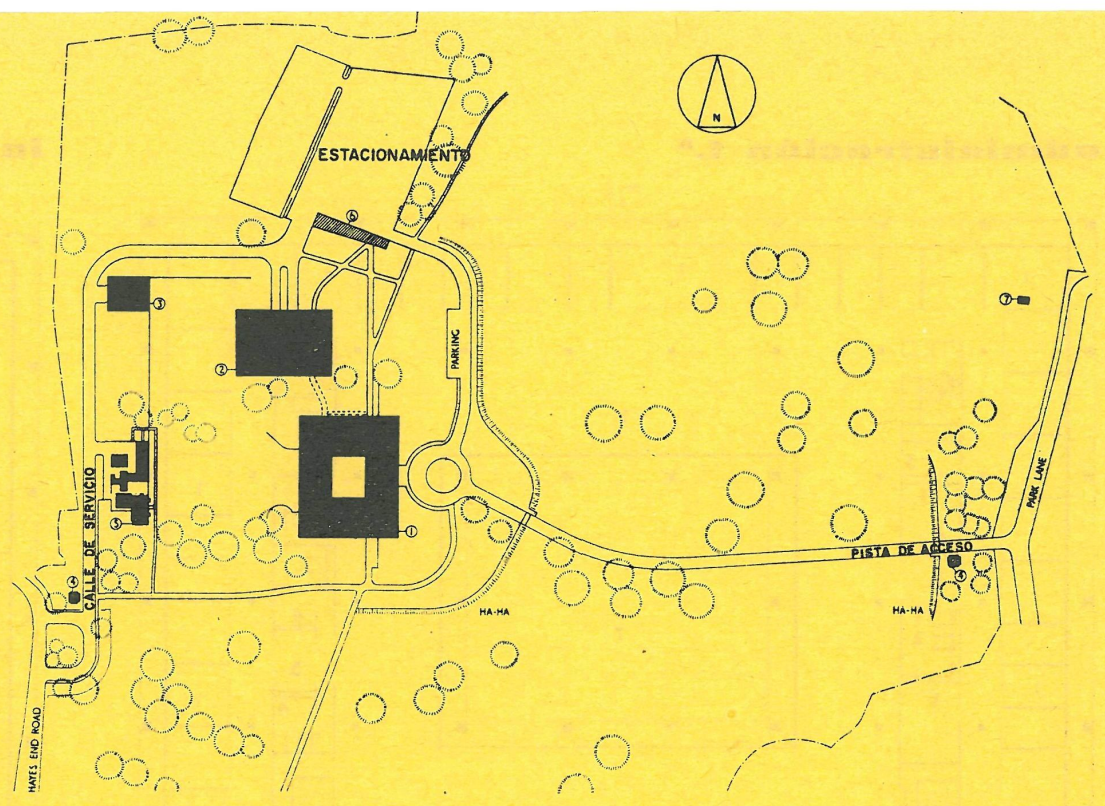

\section{administeración}

\section{plomentomia} 1. Terraza. -2 . Lavaplatos. -3 . Bar. -4 . Te-
letipo. -5 . Máquinas de copias. -6 . Correo. 7. Acceso al túnel.-8. Preparación de vegetales.-9. Tunel de enlace para personal. 10. Nave número 1.-11. Estanque.-12. Ca mareros.-13. Descanso.-14. Almacén.-15. Cocina. - 16. Ropa blanca. -17 . Despacho 18. Ases. Recepción - 24. Nave número 2-25. -23 . sejo de administración.-26. Despensa - 27. Comedor dirección.-28. Sala de proyec cíon.-29. Consejos. -30. Secretaría.-31. Director.
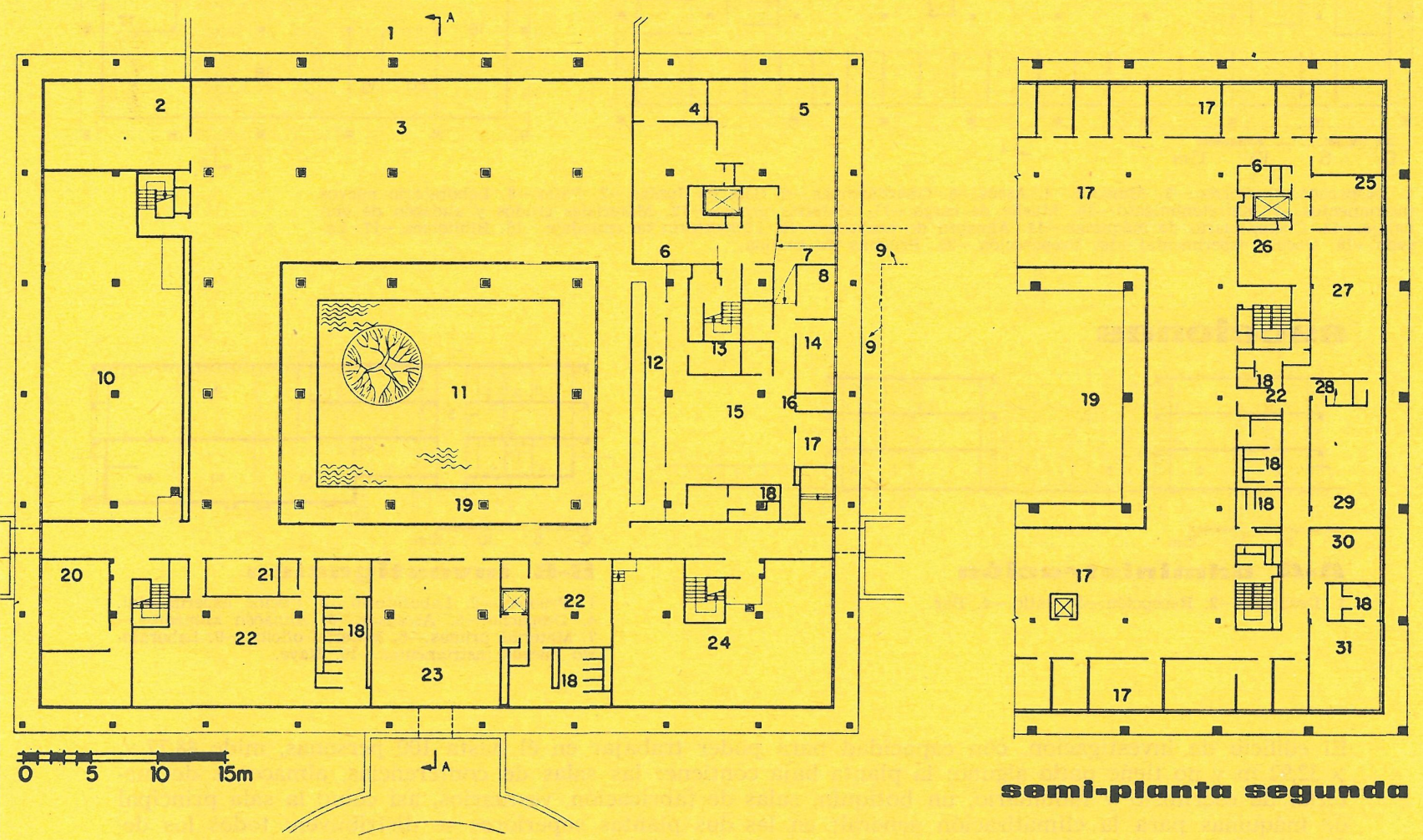

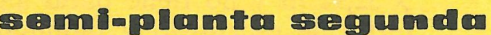

Heinz Co., sino además han suministrado un espacio adicional para la fabricación. Al estudiar la composición estética del conjunto, las torres de refrigeración de la instalación de aire acondicionado, los depósitos de agua, y los transformadores fueron agrupados de modo que no quedaran vistos.

El edificio de la administración, que mide $60,96 \times 48,77 \mathrm{~m}$ y tiene capacidad para que puedan trabajar en él, unas 450 personas, se alza en torno a un patio abierto; en él ha sido construido un estanque con un gracioso islote que contrasta con la seriedad de la estructura circundante.

En su planta inferior los espacios destinados a comedor y recepción han sido también organizados al rededor de dicho patio. Las dos plantas superiores están destinadas a oficinas, dando unas al patio interior y otras al parque. La planta alta aloja, asimismo, el despacho del director-gerente, la sala de juntas $\mathrm{y}$ un comedor con una cocina comunicada con la principal de la planta baja por un montacargas. 


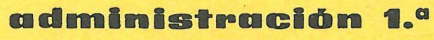

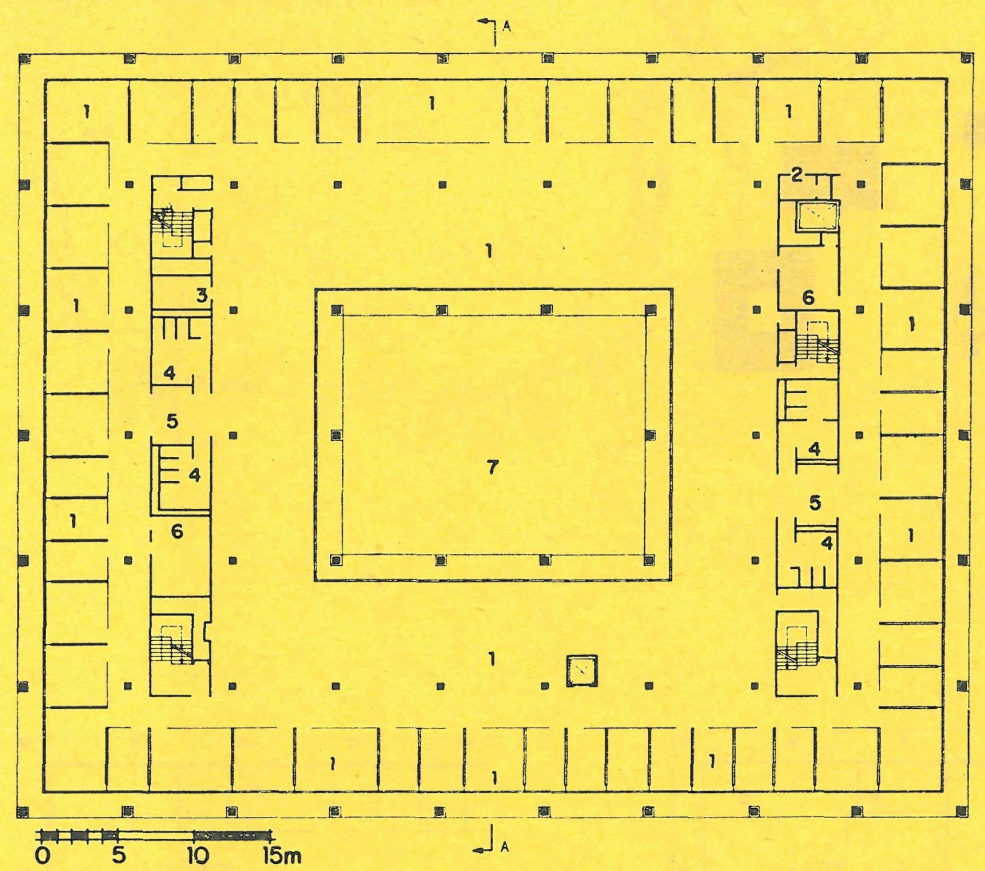

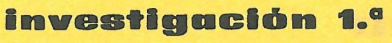

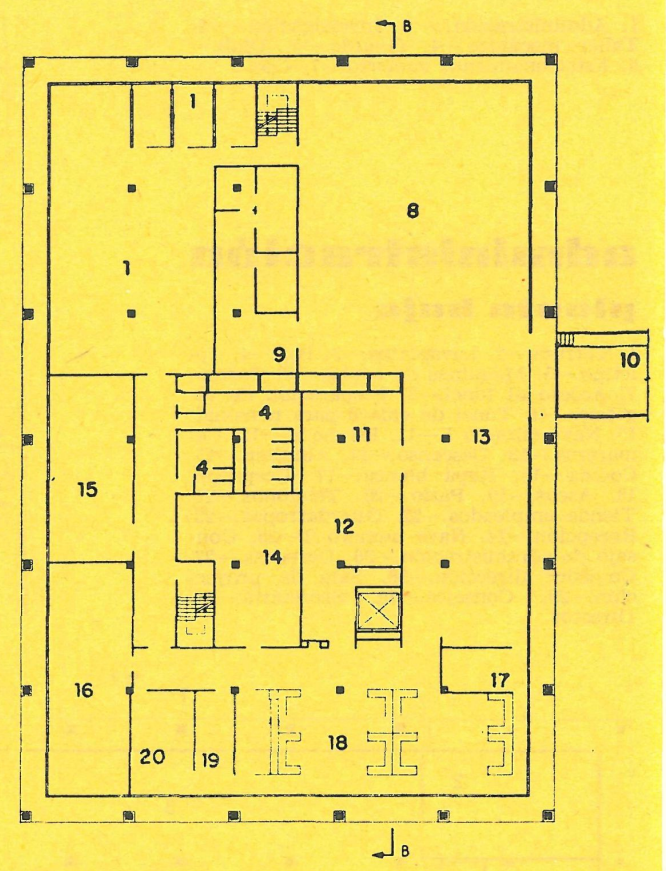

1. Despachos.-2. Correo.-3. Almacén.-4. Aseos.-5. Guardarropas.-6. Sala de Juntas.-7. Patio.-8. Laboratorio nuevos instrumentos. - 9. Entretenimiento.-10. Muelle de carga.-11. Materias primas. -12 . Materiales crudos y almacén de emvado.-18. Cocina experimental.-19. Preparación.-20. Pruebas de comida.

\section{secciones}

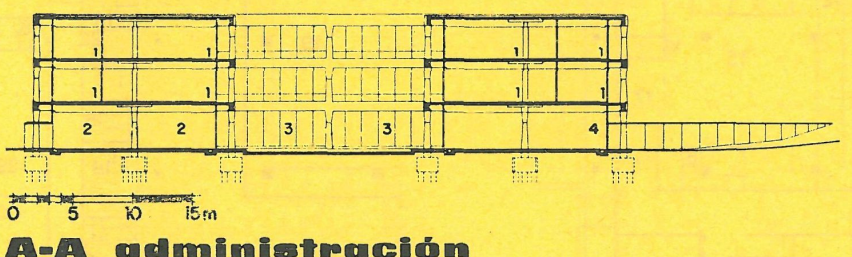

1. Despacho.-2. Recepción.-3. Patio.-4. Bar.

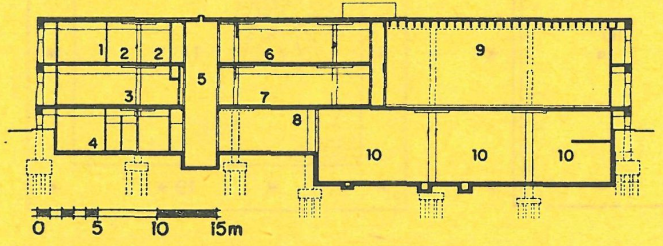

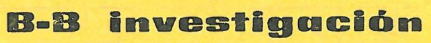

1. Pruebas.-2. Laboratorio.-3. Cocina experimental. ascensor. -6. Almacén alimentos. Materias primas.-8. Material oficina.-9. Laborato io nuevos instrumentos. -10 . Nave.

El edificio de investigación, con capacidad para poder trabajar en él hasta 100 personas, mide $48,77 \times$ $\times 32,92 \mathrm{~m}$ y no tiene patio alguno; la planta baja contiene: las salas de conferencias, almacenes de material de escritorio y mobiliario, un botiquín, salas de fabricación, vestuarios, así como la sala principal de máquinas para la climatización general; en las dos plantas superiores se distribuyen: todos los departamentos de investigación y de ensayos, así como una serie de laboratorios destinados a investigación en el campo de la alimentación, análisis, envase, bacteriología, transmisión de calor, etc. Junto a estos laboratorios están las salas de ensayos y una biblioteca de consulta. En la primera planta hay un local dedicado a «cocina experimental» con una serie de unidades de cocinas individuales a escala doméstica; y colindando con ella, una sala experimental de máquinas que desemboca a su vez en una tienda piloto.

Todas las dependencias de ambos edificios, cuya planta tiene un área total de $11.611 \mathrm{~m}^{2}$, están acondicionados: las oficinas mediante elementos colocados bajo los antepechos de las ventanas, y las zonas interiores por unidades independientes.

Los inmuebles también disponen de una eficiente red de instalaciones especiales: protección contra incendios; sistema telefónico en el que no es preciso pasar a través del cuadro de distribución para llamadas exteriores, y se emplea el mismo aparato para comunicaciones interiores y exteriores; etc. En ellos fue estudiado detenidamente el funcionamiento del servicio de correos, de modo que la correspondencia se reciba en la estación receptora de objetos importantes del edificio de investigación, pasando luego por el enlace subterráneo a la sala de correspondencia, sita en la esquina noroeste de la planta 
baja del edificio de administración, desde donde se distribuye a todos los departamentos por medio de un montacargas que también recoge la correspondencia de salida; conectado con dicha sala de correspondencia está el departamento de copias y teleimpresión.

Destaca en este conjunto la estructura prefabricada, en hormigón armado. Los soportes que bordean el perímetro exterior de cada edificio, diseñados con una «forma» atrevida -cruciforme-, han sido dejados "vistos» al igual que las cabezas de las vigas, mostrando una textura áspera y acusando el árido - de color pardo-

Los cerramientos aparecen retranqueados $1,52 \mathrm{~m}$ y fueron realizados a base de muro-cortina construido con vidrio y armazón de aluminio; dicho vidrio presenta un tono gris oscuro que desde el exterior parece casi negro e imprime a las fachadas una apariencia cálida por contraste con el del aluminio anodizado de las ventanas, ayudando al propio tiempo a reducir el efecto nocivo del brillo sobre los que trabajan en el interior.

Fueron cuidadosamente estudiados y planteados los accesos: los empleados que vienen en vehículo ingresan en las edificaciones desde el aparcamiento, descendiendo por una rampa sita en el lado norte; los que llegan a pie pueden entrar bajando por otra rampa semejante existente en el lado sur; estas entradas fueron determinadas pensando en que los empleados suban por una de las cuatro escaleras a sus puestos de trabajo, sin que perturben el funcionamiento de las plantas principales. El acceso de los visitantes a las edificaciones se efectúa por un largo paseo que atraviesa el parque, llegando en primer lugar al nivel de la planta baja, debido al perfil que presenta el terreno, y de aquí por la entrada principal ingresan en el salón de recepción.

En cuanto a la decoración interior, la ambientación y los muebles fueron diseñados para que armonizasen con el conjunto; y como aportación de las artes plásticas aparecen pinturas abstractas actuales por todo el edificio de administración.

alreadio

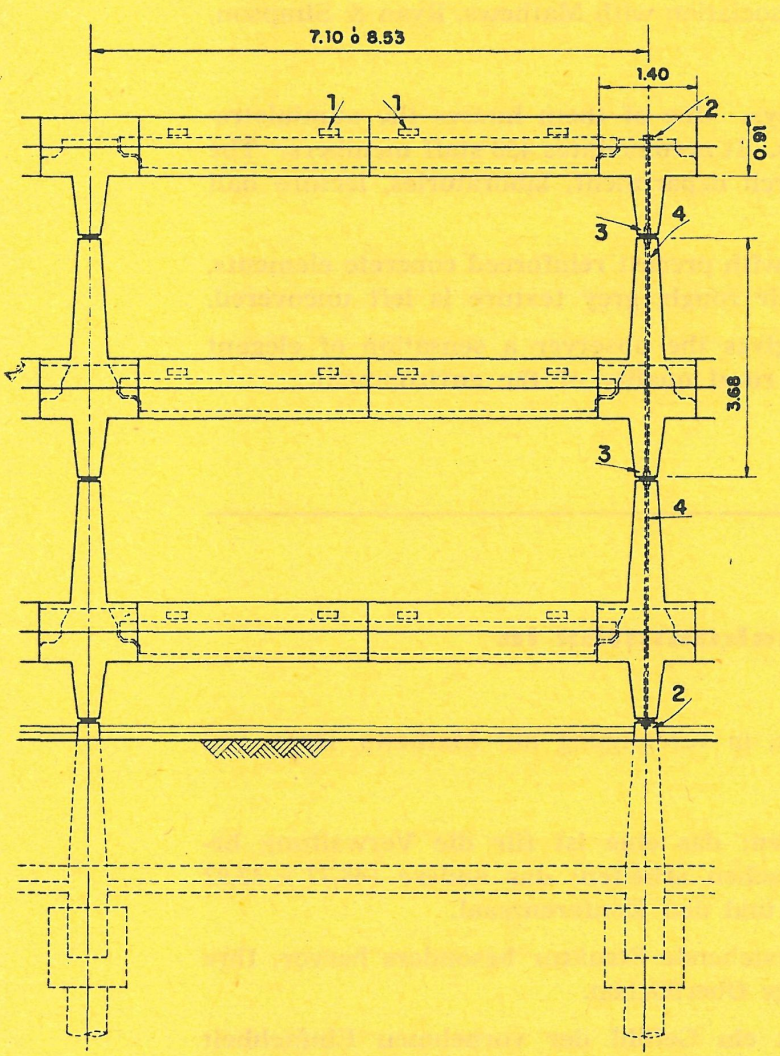

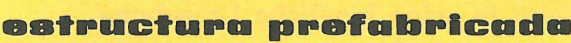
detalle
Sccelón por Ia vign do bordo

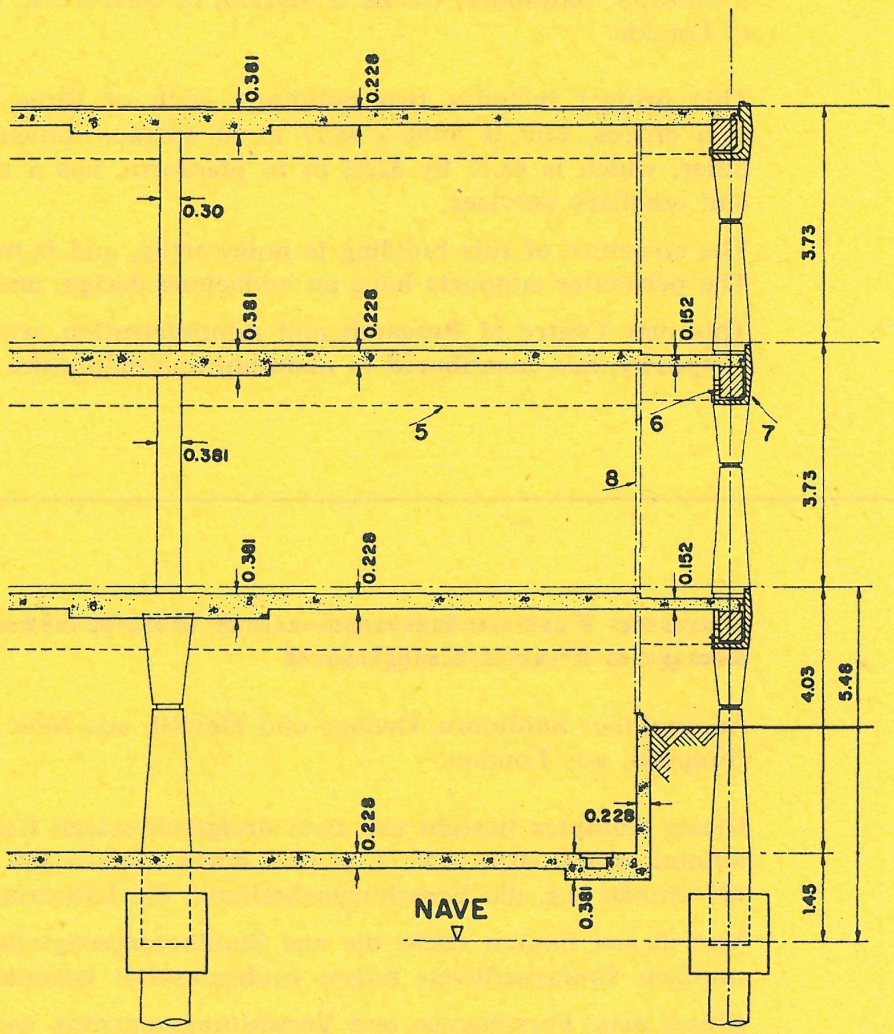
1. Asas. -2. Anclajes. -3. Conector.-4. Barra de $1{ }^{1 / 4^{\prime \prime}}-5$. Pobrimiento.-8. Línea de acristalamiento. 


\section{rósumé}

\section{Wouveau comtre de recherche ot d"oudmimistrution i Hages Parle-trumde Bretugne}

Architectes: Skidmore, Owings and Merrill, de New York, en association avec Mathews, Ryan and Simpson, de Londres

Cet emseble comprend deux édifices, de trois étages. L'un d'eux, de $60 \mathrm{~m} 96 \times 48 \mathrm{~m} \mathrm{77,} \mathrm{est} \mathrm{occupé}$ par les bureaux d'administration, où 450 personnes peuvent travailler. L'autre, de $48 \mathrm{~m} 77 \times 32 \mathrm{~m}$ 92 est destiné au département de recherche, aux laboratoires, à la salle de conférences, etc.

Leur structure préfabriquée est remarquable. Exécutés en béton armé, les supports périmetraux, d'une forme hardie et laissés à découvert, montrent leur texture rugueuse et l'agrégat de couleur brune.

Ce nouveau centre de recherche et d'administration, qui provoque chez le spectateur une sensation d'élégance et de simplicité, a contribué à respecter, conserver et rehausser le caractère rural de l'emplacement.

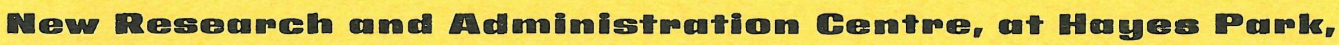 Breitroim}

Architects: Skidmore, Owins \& Merrill, of New York, in association with Mathews, Ryan \& Simpson, of London

This project includes two buildings, each of three storeys. One of them houses the administration offices, and is $60.96 \times 48.77 \mathrm{~m}$ in surface dimensions. It accomodates 450 staff members. The other, which is 48.77 by $32.92 \mathrm{~m}$ in planform, has a research department, laboratories, lecture hall and auxiliary services.

The structure of this building is noteworthy, and is made with precast reinforced concrete elements. The perimeter supports have an audacious design, and their rough, grey texture is left uncovered.

This new Centre of Research and Administration, which gives the observer a sensation of elegant simplicity, has contributed to maintain and emphasize the rural quality of the environment.

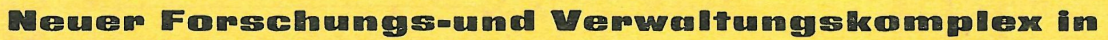

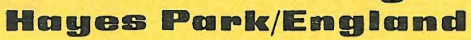

Architekten: Skidmore, Owings and Merrill, aus New York, in vereinigung mit Mathews, Ryan and Simpson, aus London.

Dieser Komplex besteht aus zwei dreigeschossigen Gebäuden; das eine ist für die Verwaltung bestimmt, misst $60,96 \times 48,77 \mathrm{~m}$ und darin können 450 Menschen arbeiten; das andere $(48,77 \times 32,92$ m) enthält u.s. die Forschungsabteilung, die Laborräume, und den Konferenzsaal.

Von diesen Bauten sticht die aus Stahlbetonfertigteilen bestehende Struktur besonders hervor. Ihre mutigen Umfagsstützen zeigen rauhgelassene braunkörnige Oberflächen.

Dieses neue Forschungs- und Verwaltungszentrum, welches ein Gefühl der vornehmen Einfachheit ausstrahlt, fügt sich in respektvoller, gar unterstreichender Weise in seine ländliche Umgebung. 